\title{
Outcome after External Decompression for Massive Cerebral Infarction
}

\author{
Kyoji SaKaI, Kazuko IWAHASHI, Kinya Terada, Yuji GoHDA, \\ Masaru SAKURAI, and Yuzo MATSUMOTO
}

Department of Neurosurgery, Kagawa Prefectural Central Hospital, Takamatsu

\begin{abstract}
Acute ischemic stroke involving the entire vascular distribution of a carotid or middle cerebral artery can cause massive cerebral edema. This study evaluated external decompression for the treatment of massive stroke and analyzed possible prognostic factors. Twenty-four patients with acute massive cerebral infarction, which had progressed to tentorial herniation and impending death, underwent external decompression after medical therapy failed to achieve an effective response. The neurological outcome 2 months after surgery using the Glasgow Outcome Scale was severe disability in 14 patients, vegetative state in two, and death in eight. The overall mortality was $33 \%$. Various characteristics (age, sex, etiology, side of hemispheric infarction, pupillary asymmetry, Japan Coma Scale, distribution of infarction, hemorrhagic infarction, midline shift, tentorial herniation) were evaluated to determine the factors associated with high mortality after surgical intervention. There was no statistically significant relationship between any variable and mortality. Mortality was especially high in the patients with preoperative consciousness level of $\mathbf{2 0 0}$, anterior, middle, and posterior cerebral artery territory infarction, and stage III of tentorial herniation. Postoperatively, all patients with severe disability returned to a clear level of consciousness. Six patients with dominant hemisphere stroke had some measure of communicative skills in spite of aphasia. External decompression is a life-saving treatment for patients with massive cerebral infarction and can provide a reasonable quality of life even for those with dominant hemisphere strokes. Decompressive surgery should be considered and performed as soon as possible if computed tomography demonstrates signs of descending tentorial herniation.
\end{abstract}

Key words: cerebral infarction, stroke, brain edema, surgical treatment

\section{Introduction}

Ischemic stroke is the most common disease of the brain as well as the prevalent cause of brain-related death. Acute ischemic infarction involving the entire vascular distribution of a carotid or middle cerebral artery (MCA) can cause massive unilateral hemispheric cerebral edema and may result in tentorial herniation and death. Medical treatment is frequently ineffective for such severe brain swelling. Decompressive surgery may be an effective therapeutic alternative when medical therapy is ineffective. Since 1974, 134 patients have been treated with decompressive surgery for supratentorial massive cerebral infarction., ${ }^{2,3,6,8,10-14,18-22,24,25,27)}$ This study describes the clinical course of 24 patients treated with external decompression and analyses the possi- ble prognostic factors.

\section{Subjects and Methods}

806 patients with acute cerebral infarction were admitted to our hospital between 1986 and 1995. Most patients in this series were admitted immediately after the onset without prior selection. We excluded cases of symptomatic severe vasospasm following aneurysmal subarachnoid hemorrhage. All patients with an extended space-occupying hemispheric infarction covering at least the MCA territory received general treatment according to Table 1 . None of the patients had received barbiturate coma therapy or continuous intracranial pressure (ICP) monitoring. Decompressive surgery was considered when decreasing level of consciousness and/or the begin- 


\section{Table 1 General treatment protocol}

Elevation of the head $\left(20^{\circ}-30^{\circ}\right)$

Adequate ventilation and oxygenation $\left(\mathrm{PaCO}_{2} 30-40\right.$ $\mathrm{mmHg}, \mathrm{PaO}_{2}>100 \mathrm{mmHg}$ )

Osmotic therapy with glycerol $(10 \%, 500-1000 \mathrm{ml} /$ day $)$

Systolic blood pressure of $120-200 \mathrm{mmHg}$

Endotracheal intubation and mechanical ventilation in the case of decreased level of consciousness with respiratory distress

Avoid hyperglycemia

Avoid hyperthermia

ning of unilateral mydriasis and computed tomography (CT) findings of tentorial herniation occurred, despite the conservative therapy. None of the patients showed bilateral fixed and dilated pupils at the time of surgical intervention. Informed consent was obtained from relatives for all surgically treated patients. Only patients less than 80 years of age (with one exception) were considered for surgical treatment. Patients with additional severe medical complications that raised the perioperative risk were excluded from surgical treatment.

A total of 24 patients with supratentorial massive cerebral infarction were treated with external decompression consisting of extensive hemicraniectomy with removal of frontal, temporal, and parietal bone and wide dural augmentation with autologous temporal fascia and periosteum. A huge intracerebral hematoma was also evacuated in one patient with massive hemorrhagic infarction. The dominance of hemisphere was not considered for the indication of surgery. The etiological classification of acute ischemic stroke was determined according to the National Institute of Neurological Disorders and Stroke. ${ }^{15)}$

CT and cerebral angiography were performed. Before the surgery, serial CT scans were performed at the following times: a) immediately after hospital admission, b) every 12 or 24 hours after admission, and c) when the patient deteriorated to a consciousness level of at least 20 on the Japan Coma Scale, ${ }^{17]}$ and/or unilateral mydriasis appeared. Midline shift and the stage of tentorial herniation were evaluated from the last preoperative CT findings. Craniectomy was started within 2-3 hours after the appearance of tentorial herniation on CT scans. Midline shift based on horizontal displacement of the septum pellucidum, and the stage of descending tentorial herniation according to a stage modified from Stovring ${ }^{23)}$ were evaluated on CT scans (Table 2). Level of consciousness in the acute stage was evaluated by the Japan Coma Scale. ${ }^{17)}$

Neurological outcome was evaluated at 2 months

\section{Table 2 Stages of tentorial herniation}

Stage I (impending herniation):

encroachment upon the lateral aspect of the suprasellar cistern

Stage II (actual herniation): rotation and shift of the brain stem

Stage III (advanced herniation):

obliteration of cisternal spaces at the tentorial level

postsurgery using the Glasgow Outcome Scale. ${ }^{9)}$ Age, sex, etiology, side of hemispheric infarction, pupillary asymmetry, Japan Coma Scale, distribution of infarction, hemorrhagic infarction, midline shift, and tentorial herniation were evaluated to identify which characteristics were associated with high mortality after surgical intervention using Fisher's exact test.

\section{Results}

There were 13 males and 11 females, aged from 29 to 83 years (mean 63.6 years). Acute massive cerebral infarction occurred in 13 right hemispheres and in 11 left ones. Twenty patients had embolic infarction and four had thrombotic infarction. Clinical risk factors included atrial fibrillation $(n=17)$, arterial hypertension ( $\mathrm{n}=8$ ), mitral valve disease $(\mathrm{n}=4)$, hypertrophic cardiomyopathy $(\mathrm{n}=1)$, diabetes mellitus ( $\mathrm{n}=1)$, and administration of oral contraceptives $(\mathrm{n}=1)$.

Preoperatively, all 24 patients had developed cloudy consciousness; the consciousness level was 20 or 30 in 12 patients, 100 in 11, and 200 in one. Eighteen patients (75\%) developed asymmetric pupils. Mydriasis was seen ipsilateral to the stroke in 11 cases and contralateral in one. CT demonstrated hypodensity of only the MCA territory in 16 patients, of the anterior cerebral artery (ACA) and MCA territories in five, and of the ACA, MCA, and posterior cerebral artery (PCA) territories in three. Cerebral angiography was performed in 18 of 24 patients, revealing occlusion of the proximal MCA trunk in seven patients and occlusion of the distal intracranial internal carotid artery in 11 patients. Collateral circulation was poor because no or few leptomeningeal collaterals were seen. The mean interval to surgery was 39 hours in patients with embolic infarction and 105 hours in those with thrombotic infarction.

The neurological outcome was severe disability in 14 patients, vegetative state in two, and death in eight. The overall mortality was $33 \%$. Three deaths were secondary to non-neurological causes, includ- 
Table 3 Various patient characteristics and mortality

\begin{tabular}{|c|c|c|}
\hline Characteristic & $\begin{array}{l}\text { No. of } \\
\text { patients }\end{array}$ & $\begin{array}{c}\text { Mortality } \\
(\%)\end{array}$ \\
\hline \multicolumn{3}{|l|}{ Age } \\
\hline$<60$ yrs & 10 & 40 \\
\hline$>60 \mathrm{yrs}$ & 14 & 29 \\
\hline \multicolumn{3}{|l|}{ Sex } \\
\hline $\mathrm{M}$ & 13 & 38 \\
\hline $\mathrm{F}$ & 11 & 27 \\
\hline \multicolumn{3}{|l|}{ Etiology } \\
\hline embolic & 20 & 35 \\
\hline thrombotic & 4 & 25 \\
\hline \multicolumn{3}{|l|}{ Hemisphere } \\
\hline rt & 13 & 38 \\
\hline lt & 11 & 27 \\
\hline \multicolumn{3}{|l|}{ Neurological findings: } \\
\hline \multicolumn{3}{|l|}{ Pupillary asymmetry } \\
\hline present & 18 & 39 \\
\hline absent & 6 & 17 \\
\hline \multicolumn{3}{|l|}{ Japan Coma Scale } \\
\hline 20 or 30 & 12 & 42 \\
\hline 100 & 11 & 18 \\
\hline 200 & 1 & 100 \\
\hline \multicolumn{3}{|l|}{ CT findings: } \\
\hline \multicolumn{3}{|l|}{ Distribution of infarction } \\
\hline MCA territory & 16 & 25 \\
\hline $\mathrm{ACA}+\mathrm{MCA}$ & 5 & 40 \\
\hline $\mathrm{ACA}+\mathrm{MCA}+\mathrm{PCA}$ & 3 & 67 \\
\hline \multicolumn{3}{|l|}{ Hemorrhagic infarction } \\
\hline present & 6 & 17 \\
\hline absent & 18 & 39 \\
\hline \multicolumn{3}{|l|}{ Midline shift } \\
\hline$<10 \mathrm{~mm}$ & 7 & 29 \\
\hline$>10 \mathrm{~mm}$ & 17 & 35 \\
\hline \multicolumn{3}{|l|}{ Tentorial herniation } \\
\hline stage I & 7 & 14 \\
\hline stage II & 13 & 38 \\
\hline stage III & 4 & 50 \\
\hline Total & 24 & 33 \\
\hline
\end{tabular}

ACA: anterior cerebral artery, CT: computed tomography, MCA: middle cerebral artery, PCA: posterior cerebral artery.

ing pulmonary embolus ( $n=2$ ) and massive intestinal bleeding $(n=1)$. The characteristics of the 24 patients treated with decompressive surgery are shown in Table 3. There was no statistically significant relationship between any of the variables (age, sex, etiology, side of hemispheric infarction, pupillary asymmetry, Japan Coma Scale, distribution of infarction, hemorrhagic infarction, midline shift, tentorial herniation) and mortality. Mortality was especially high in patients with preoperative consciousness level of 200, ACA + MCA + PCA territory infarction, and stage III of tentorial herniation (mortality $=100 \%, 67 \%$, and $50 \%$, respectively).

\section{Discussion}

There is continuing controversy about the benefits of urgent decompressive surgery for acute massive cerebral infarction. The main goals of decompression are preservation of life, and recovery to a clear level of consciousness. Improvement of functional neurological deficits such as hemiplegia and aphasia is the third goal. Of our 24 patients, 14 patients with severe disability rapidly awoke to the admission level of function after the surgery. Six patients who had dominant hemisphere strokes suffered from aphasia but recovered to a clear level of consciousness and had some measure of communicative skills. All patients with severe disability, including those with dominant hemisphere strokes, and their near relatives reported an acceptable quality of life.

Mortality was especially high in the patients with preoperative consciousness level of 200, ACA + MCA + PCA territory infarction, and stage III of tentorial herniation. A consciousness level of 200 or stage III of tentorial herniation may be too late to start decompressive surgery. Multilobular infarction involving the PCA territory may cause more massive brain swelling and develop into tentorial herniation, or PCA territory infarction may be secondary to kinking of a depressed PCA over the free margin of the tentorial hiatus on the same side as the descending herniation. ACA + MCA + PCA territory infarction may be a contraindication to decompressive surgery. Drowsiness and pupillary asymmetry are thought to be the most consistent and specific signs of impending herniation. We believe it is of prime importance that CT scans should be taken as soon as possible when such clinical conditions are found. Tentorial herniation is the primary neurological cause of death in most studies. ${ }^{1,7.16)}$ If decompression is carried out before the tentorial herniation develops to stage II or III, the outcome may be better. Decompression should not be delayed so long that irreversible brain stem damage occurs. When CT shows that the parenchymal hypodensity covers more than $50 \%$ of the MCA territory, the incidence of fatal brain edema is $85 \%$. ${ }^{26)}$ Postinfarction cerebral edema resulting in tentorial herniation and death often occurs within 48 hours." Prophylactic external decompression may be carried out for such patients, especially young patients, in whom the homogeneous low density area with mild edema appears over the whole MCA territory on CT scans 24 to 48 hours after the onset. Recently, brain tissue shifts, rather than elevated ICP, were proposed as a more likely cause of initial deterioration from large hemispheric infarction with edema. ${ }^{5}$ Conventional ICP-lowering ther- 
apies such as hyperventilation and mannitol administration could accentuate pressure differentials between the injured and uninjured hemispheres and tissue shifts. Therefore, they are of questionable rationale and of no proven benefit for this disease. In contrast, surgical decompression is a rational approach to minimizing tissue shifts from regional brain edema. ${ }^{5}$

134 patients have been treated with decompressive surgery for massive cerebral infarction since $1974 .^{2,3,6,8,10-14,18-22,24,25,27)}$ We show 80 cases with the side of hemispheric infarction and outcome after surgery clearly described. ${ }^{2,3,8,11-13,18,19,21,25,27]}$ Three kinds of decompressive surgery have been reported: only external decompression, only internal decompression, and internal plus external decompressions. Internal decompression includes resection of only the infarcted tissue (strokectomy) and more extensive resection with hippocampectomy. Extensive internal decompression with hippocampectomy is advocated to immediately relieve peduncle compression and is considered more effective in preserving life than external decompression. ${ }^{6,24}$ Sixty-four patients underwent external decompression and 16 underwent internal or internal plus external decompression (Table 4). The outcome from internal or external plus internal decompression seems to be better than that from only external decompression. In the present study, there were no patients who recovered to a functionally independent status 2 months postsurgery. The outcomes in our series were poor compared to the previous series. We think there are two reasons: the early evaluation of the neurological outcome, and the high mean age of our patients. Younger patients can make exceptional recoveries to independent status. Recently, a prospective study of 53 patients with massive cerebral infarction suggested that external decompression may improve the neurological outcome and reduce the

Table 4 Summary of reported cases: Comparison between external decompression and internal decompression or external plus internal decompression

\begin{tabular}{cccccc}
\hline & & No. of & Mean age & \multicolumn{3}{c}{ Outcome } \\
Surgery & patients & $\begin{array}{c}\text { (yrs) } \\
\text { Good }\end{array}$ & Poor & Dead \\
\hline $\begin{array}{c}\text { External } \\
\text { decompression }\end{array}$ & 64 & 50 & 19 & 23 & 22 \\
$\begin{array}{c}\text { Internal } \\
\text { decompression } \\
\text { or external + } \\
\text { internal } \\
\text { decompression }\end{array}$ & 16 & 46 & 12 & 2 & 2 \\
\hline
\end{tabular}

Table 5 Summary of reported cases: Comparison between non-dominant hemispheric infarction and dominant hemispheric infarction

\begin{tabular}{lccrrr}
\hline \multirow{2}{*}{$\begin{array}{c}\text { Side of } \\
\text { infarction }\end{array}$} & $\begin{array}{c}\text { No. of } \\
\text { patients }\end{array}$ & $\begin{array}{c}\text { Mean age } \\
\text { (yrs) }\end{array}$ & \multicolumn{3}{c}{ Outcome } \\
\cline { 5 - 6 } & & & Good & Poor & Dead \\
\hline $\begin{array}{l}\text { Non-dominant } \\
\text { Dominant }\end{array}$ & 64 & 51 & 27 & 19 & 18 \\
& 16 & 44 & 4 & 6 & 6 \\
\hline
\end{tabular}

mortality. ${ }^{19)}$ Moreover, in the rat model of malignant cerebral hemispheric stroke, decompressive craniectomy reduced mortality and morbidity. If performed early after MCA occlusion, it also significantly reduced the infarction size. ${ }^{4)}$

Many neurosurgeons and neurologists believe that massive infarction in the dominant hemisphere is a contraindication to such intervention. In previous series, 16 patients presenting with the dominant hemispheric infarction and clinical signs of tentorial herniation underwent decompressive surgery. Only four of 10 surviving patients were able to recover to largely independent status. The outcome of patients with dominant hemispheric infarction seems to be poor compared to patients with nondominant hemispheric infarction (Table 5).

In conclusion, we think that external decompression is a life-saving treatment for massive cerebral infarction and can provide a reasonable quality of life even for dominant hemisphere strokes. The timing of surgery is very important. Decompressive surgery should be one of the major treatments for patients with massive stroke.

\section{Acknowledgments}

The authors would like to thank Mr. Thomas D. Bauer for editorial assistance.

\section{References}

1) Bounds JV, Wiebers DO, Whisnant JP, Okazaki H: Mechanisms and timing of deaths from cerebral infarction. Stroke 12: 474-477, 1981

2) Carter BS, Ogilvy CS, Candia GJ, Rosas HD, Buonanno F: One-year outcome after decompressive surgery for massive nondominant hemispheric infarction. Neurosurgery 40: 1168-1176, 1997

3) Delashaw JB, Broaddus WC, Kassell NF, Haley EC, Pendleton GA, Vollmer DG, Maggio WW, Grady MS: Treatment of right hemispheric cerebral infarction by hemicraniectomy. Stroke 21: 874-881, 1990

4) Doerfler A, Forsting $M$, Reith W, Staff $C$, Heiland S, Schäbitz W-R, von Kummer R, Hacke W, Sartor K: 
Decompressive craniectomy in a rat model of "malignant" cerebral hemispheric stroke: experimental support for an aggressive therapeutic approach. J Neurosurg 85: 853-859, 1996

5) Frank II: Large hemispheric infarction, deterioration, and intracranial pressure. Neurology 45: 12861290, 1995

6) Fujita K, Tamaki N, Matsumoto S, Nagao T: [Unilateral inferior temporal lobectomy with hippocampectomy for acute ischemic brain edema]. No Shinkei Geka 10: 849-855, 1982 (Jpn, with Eng abstract)

7) Hacke W, Schwab S, Horn M, Spranger M, De Georgia $M$, von Kummer R: Malignant middle cerebral artery territory infarction. Clinical course and prognostic signs. Arch Neurol 53: 309-315, 1996

8) Ivamoto HS, Numoto M, Donaghy RMP: Surgical decompression for cerebral and cerebellar infarcts. Stroke 5: 365-370, 1974

9) Jennett B, Bond M: Assessment of outcome after severe brain damage. A practical scale. Lancet 1: 480484,1975

10) Jourdan C, Convert J, Mottolese C, Bachour E, Gharbi S, Artru F: [Clinical benefit of decompressive hemicraniectomy for non-medically controlled intracranial hypertension]. Neurochirurgie 39: 304-310, 1993 (Fre, with Eng abstract)

11) Kakita K, Miyazaki T, Kadowaki H, Izawa M, Kubota S, Asakura T, Kitamura K: [A trial of surgical management of brain edema in cerebral infarction. A review with our own experiences in 31 cases]. No Shinkei Geka 4: 277-283, 1976 (Jpn, with Eng abstract)

12) Kalia KK, Yonas $H$ : An aggressive approach to massive middle cerebral artery infarction. Arch Neurol 50: $1293-1297,1993$

13) Kondziolka D, Fazl M: Functional recovery after decompressive craniectomy for cerebral infarction. Neuгоsurgery 23: 143-147, 1988

14) Martins LF, Da Costa V, Da Costa J, De Melo-Souza SE: [Temporal lobectomy in ischemic infarction with mass effect]. Arq Neuropsiquiatr 51: 118-124, 1993 (Port, with Eng abstract)

15) National Institute of Neurological Disorders and Stroke Ad Hoc Committee: Classification of cerebrovascular diseases III. Stroke 21: 637-676, 1990

16) Ng LKY, Nimmannitya J: Massive cerebral infarction with severe brain swelling. A clinicopathological study. Stroke 1: 158-163, 1970

17) Ohta T, Waga S, Handa $H$, Saito I, Takeuchi K, Suzuki ], Takaku A: [New grading of level of disordered consciousness]. No Shinkei Geka 2: 623-627, 1974 (Jpn, with Eng abstract)

18) Rengachary SS, Batnitzky S, Morantz RA, Arjunan K, Jeffries $B$ : Hemicraniectomy for acute Inassive cerebral infarction. Neurosurgery 8: 321-328, 1981

19) Rieke K, Schwab S, Krieger D, von Kummer R, Aschoff A, Schuchardt V, Hacke W: Decompressive surgery in space-occupying hemispheric infarction: results of an open, prospective trial. Crit Care Med 23: $1576-1587,1995$
20) Saito I, Segawa $H$, Shiokawa $Y$, Taniguchi $M$, Tsutsumi K: Middle cerebral artery occlusion: correlation of computed tomography and angiography with clinical outcome. Stroke 18: 863-868, 1987

21) Shiogai $T$, Tamagawa $T$, Hara $M$, Ogashiwa $M$, Takeuchi K: [Indications for surgical decompression in severe cerebral infarction]. No Socchu 3: 259-267, 1981 (Jpn, with Eng abstract)

22) Steiger HJ: Outcome of acute supratentorial cerebral infarction in patients under 60. Development of a prognostic grading system. Acta Neurochir (Wien) 111: $73-79,1991$

23) Stovring J: Descending tentorial herniation: findings on computed tomography. Neuroradiology 14: 101105,1977

24) Tsuruno T, Takeda M, Imaizumi T, Tanooka A: [Internal decompression with hippocampectomy for massive cerebral infarction]. No Shinkei Geka 21: 823827, 1993 (Jpn, with Eng abstract)

25) Ueno K, Oosato T, Sasaki H, Nomura M: [Prophylactic external decompression for massive cerebral infarction]. No Shinkei Geka 12: 261-267, 1984 (Jpn, with Eng abstract)

26) von Kummer R, Meyding-Lamadé $U$, Forsting $M$, Rosin L, Rieke K, Hacke W, Sartor K: Sensitivity and prognostic value of early CT in occlusion of the middle cerebral artery trunk. AJNR Am J Neuroradiol 15: 9-15, 1994

27) Young PH, Smith KR Jr, Dunn RC: Surgical decompression after cerebral hemispheric stroke: indications and patient selection. South Med J 75: 473-475, 1982

Address reprint requests to: K. Sakai, M.D., Department of Neurosurgery, Kochi Prefectural Aki Hospital, 1-32 Hoei-cho, Aki, Kochi 784-0027, Japan.

\section{Commentary}

Sakai et al. report their experience with external decompression in 24 patients with massive cerebral infarction. In their series, the decision for an operation was made regarding clinical deterioration of the patient with decreasing level of consciousness and/or unilateral dilated pupils and tentorial herniation in CT scans. The overall mortality was $33 \%$ with remaining severe disability in 14 patients and a vegetative state in two. All patients who survived and reached the stage of severe disability reported an acceptable quality of life. In conclusion, the authors think that external decompression for massive cerebral infarction can be recommended as a life-saving therapy and that a reasonable quality of life can be provided. This summary is supported by the literature. The outcome is often poor with remaining severe deficits of functional psychosociological circumstances. Although some 
attempts have been made to assess outcome with scales, this question is not yet well described in literature, and remains open if the expectable outcome is in favor of the patient. The authors in this study point out a positive judgment of outcome by patients and their relatives but without using a well defined scale.

In the literature, questions about the timing of surgery are of importance. The indications are clinical deterioration with development of anisocoria or tentorial herniation found on CT scans as well as high ICP measurements. One experimental study even suggests a more favorable outcome might be possible with very early decompression. New monitoring techniques like intraparenchymal $\mathrm{PO}_{2}$ measurements may give other conclusions on the timing of surgery.

In general, the results in this study are comparable to some previously performed. There is only one prospectively designed study with a control group of not operated patients. The number of patients in the individual study is small and does not exceed 40 patients. The overall number of patients reported is around 135 in the known literature. So there is still an urgent need for a prospective multicenter study covering a greater number of patients treated following the same protocol. The presented study gives good information about a further group of patients. It cannot basically change the actual management, which is often based on subjective decisions in a very difficult, acute situation.

(See refs. 2, 4, and 19 of this article.) Ernst H. GRote, M.D. Abteilung für Neurochirurgie Universitätsklinikum Tübingen Tübingen, Germany

The authors have investigated the benefit of external decompression to rescue the patients with impending transtentorial herniation due to massive cerebral infarction. The beneficial effect of external decompression is an old but also new topic as in patients with severe head injury. After external decompression, the cerebral perfusion pressure will increase and the mechanical downward displacement and deformity of the cerebral hemisphere will also be corrected theoretically. Therefore, the beneficial effect of this surgical treatment has been sporadically reported for long time. Unfortunately, all studies were retrospective and showed no statistically significant result. The present study also showed no significant result among the variables evaluated. The mortality may be reduced by external decompression and this classical treatment will have a role as a life-saving method, as the authors mentioned. But it still remains unclear if the overall outcome is improved or not. Double blind control or prospective studies with adequate numbers of patients are necessary to determine the real benefit of this treatment.

Minoru SHIGEMORI, M.D. Department of Neurosurgery Kurume University School of Medicine Fukuoka, Japan

The aims of decompression surgerу for massive hemispheric infarction are lifesaving and improvement of the neurological deficits. The present clinical study demonstrates the benefit of decompression surgery to prevent early death from uncal herniation after massive hemispheric infarction, but the neurological outcomes are not as good as expected. Although all patients returned to a clear level of consciousness after surgery, the quality of life is not as good as might be hoped. All surviving patients suffered from severe disability, and two were vegetative. Therefore, further work needs to be done to assess the most appropriate candidates for decompression surgery for massive cerebral infarction.

Shu-Yuan YANG, M.D. Department of Neurosurgery Tianjin Medical University General Hospital Tianjin, the People's Republic of China 